\title{
editorials
}

(continued)

tion of coronary atherosclerosis must remain our primary goal.

- Increasing evidence exists showing that stress management and efforts to reduce social isolation can reduce coronary artery events and cancer mortality. In their article, "Anxiety disorders seen in primary care," beginning on page 95, Drs Brown and Baron discuss diagnosis of such disorders, including some somatic disorders that may mimic anxiety disorders. They offer suggestions regarding the appropriate time to refer such patients to a psychiatrist.

Because primary care physicians are the first-and often the only-healthcare profes- sionals such patients see, it behooves us to familiarize ourselves with this complicated and frequently misdiagnosed disorder.

THOMAS WESLEY ALLEN, DO

Editor in Chief

\section{New HIV series helps to define osteopathic physicians' role in AIDS epidemic}

As we move into the second decade of the human immunodeficiency virus (HIV) epidemic, the predictions of the past decade concerning

\section{a Creat Opportunity in a Creat Setting} Vice President, Medical Education

Brighton Medical Center in Portland... Maine's premier coastal city.

Brighton Medical Center, a 150 bed acute care hospital is seeking a full-time salaried osteopathic physician to direct the AOA accredited medical education program for medical students, interns and Orthopedic and Family Practice residents. This position offers the opportunity to enhance and reorganize the medical education program with the support of the 150 member medical staff.

The V.P. of Medical Education will join a small, energetic and innovative management team and will report to the President. The successful candidate will have clinical experience, excellent administrative and interpersonal skills and a strong interest in the challenge of the medical education process.

Portland, Maine is a small, safe city that offers an array of lifestyle amenities: ocean sailing, fishing, skiing, hiking, museums, galleries, theater, the symphony, great restaurants. If you are interested in a challenging position in a progressive hospital that offers a supportive, hospitable environment in the beautiful state of Maine, please send a cover letter and resume to:

James W. Donovan, President VPME Search 
the rate of new HIV infections and clinical manifestations of the acquired immunodeficiency syndrome (AIDS) have proved highly accurate. The infection, now well imbedded in every state, will be with us for the rest of our professional lives. As osteopathic physicians, we should now ask ourselves: What will be our role in the next decade of the HIV and AIDS epidemic?

First, as we examine our profession, we proudly realize that our strong association with family medicine serves as our primary asset and contribution to our nation's healthcare. As family practice physicians, we are widely distributed geographically, albeit often disproportionately in smaller towns and cities across the country. Accordingly, epidemiologic trends have shown alarming rates of newly diagnosed infections not only in small "nonmajor" cities, but in rural areas as well.

Although it seems unlikely that small-town America will ever experience the social upheaval commensurate with the coastal urban epidemiologic centers of this disease (New York and California), clearly even a few cases in rural areas often pose medical care problems and tremendous social strains. In my opinion, it is not a coincidence that some of our nation's darkest moments in the HIV epidemic to date have occurred in small-town, rural America. The shunning of Ryan White in Indiana and the fire bombing of three hemophiliac children in Florida are just two examples that come to mind. Family physicians can be influential in areas such as these not only by providing needed care for infected patients, but, moreover, by enlightening their communities as to how they should appropriately respond to this infectious disease.
Similarly, in larger metropolitan areas where infectious disease specialists are prevalent, general practitioners will also have a growing role. Certainly, specialists will be unable to meet the increasing demand of all newly infected patients. Here, too, the family physician can-and must-educate his or her patients regarding preventive health measures for HIV infection. This education can be done much in the way we currently deal with the preventive healthcare aspects of alcohol and tobacco abuse and hypercholesterolemia.

To be a respected source of information on this or any other disease, we osteopathic physicians must stay well versed. Keeping abreast of the latest information proves not an insignificant task, given the deluge of articles and reports on HIV and AIDS. Toward this end, the AOA Task Force on AIDS commences, with this issue of the JAOA (page 109) a series of columns discussing HIV and AIDS. Occasionally, public health guidelines or other clinical materials will supplement the columns. These columns are systematically structured to take the family physician from the initial basic problems posed by the HIV infection through the diagnosis and treatment of the disease, and, finally, to the issues raised by the dying patient.

The editorial board responsible for these columns represents a broad cross section of osteopathic physicians, including infectious disease specialists and family physicians with significant clinical experience in this area. Join us as we prepare to combat the HIV and AIDS epidemic of the 1990 s.

LEONARD H. CALABRESE, DO Chairman, AOA Task Force on AIDS Cleveland, Ohio 



\section{Bringing Together the Key Spectra of Two Antimicrobial Classes}

The Atypical Spectrum of Erythromycin ${ }^{1}$...

Plus the Gram-Negative and GramPositive Spectra of the Beta-lactams ${ }^{1}$

\begin{tabular}{|l|c|c|c|c|c|}
\hline & Mycoplasma & H. influenzae & S. pneumoniae & $\begin{array}{c}\text { S. pyogenes } \\
\text { (group A strep) }\end{array}$ & M. catarrhalis \\
\hline BIAXIN1 & $\checkmark$ & $\checkmark$ & $\checkmark$ & $\checkmark$ & $\checkmark$ \\
\hline Erythromycin $^{2}$ & $\checkmark$ & & $\checkmark$ & $\checkmark$ & $\checkmark$ \\
\hline Amoxicillin $^{2}$ & & $\checkmark$ & $\checkmark$ & $\checkmark$ & \\
\hline Augmentin $^{\circledR 2}$ & & $\checkmark$ & $\checkmark$ & $\checkmark$ & $\checkmark$ \\
\hline Ceclor $^{\circledR 2}$ & & $\checkmark$ & $\checkmark$ & $\checkmark$ & $\checkmark$ \\
\hline Ceftin $^{\circledR 2}$ & & $\checkmark$ & $\checkmark$ & $\checkmark$ & $\checkmark$ \\
\hline
\end{tabular}

\section{Reliable Bioavailability}

- Excellent tissue penetration - without sacrificing therapeutic serum levels ${ }^{1,3}$

- Can be taken with or without food ${ }^{1}$ 


\section{Excellent Clinical Success Rates ${ }^{* 11,4,5}$}

Community-Acquired Pneumonia (typical and atypical)

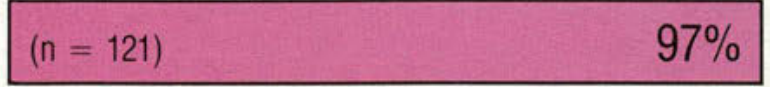

Bronchitis

$(n=85) \quad 94 \%$

Pharyngitis

$(n=222) \quad 97 \%$

Acute Maxillary Sinusitis

$(n=33) \quad 91 \%$

\section{As Effective as Ceclor ${ }^{\circledR}$, Ceftin ${ }^{\circledR}$, and Suprax ${ }^{\circledR}$ in Eradicating H. influenzae in Well-Controlled Bronchitis Studies'}

\section{Very Well Tolerated}

- Significantly less GI upset than erythromycin - equivalent to beta-lactams such as amoxicillin, Ceclor ${ }^{\circ}$, and Ceftin 1,5

NEW!

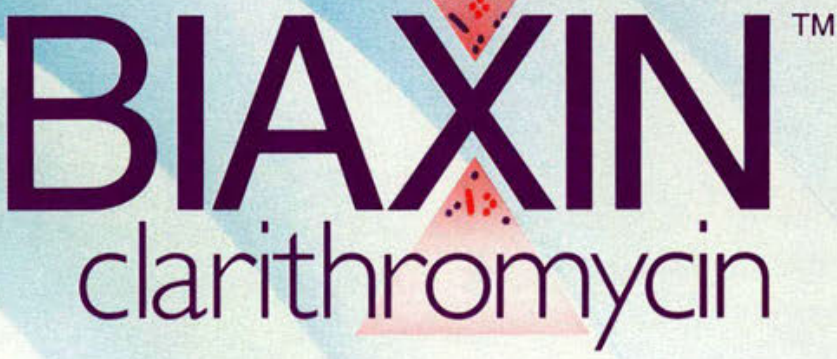

$250 \mathrm{mg}$ and $500 \mathrm{mg}$ Tablets

Spans the spectrum of erythromycin and the beta-lactams 


\section{Convenient BID Dosing Without Regard to Meals}

\begin{tabular}{|l|c|c|}
\hline \multicolumn{3}{|c|}{ Recommended Dosage } \\
\hline INFECTION & DOSAGE & DURATION \\
\hline $\begin{array}{l}\text { Lower Respiratory } \\
\text { Tract Infections: } \\
\text { Pneumonia/Bronchitis }\end{array}$ & $250-500 \mathrm{mg}$ BID & $7-14$ days \\
\hline $\begin{array}{l}\text { Upper Respiratory } \\
\text { Tract Infections: } \\
\begin{array}{l}\text { Pharyngitis/Tonsillitis/ } \\
\text { Acute Maxillary Sinusitis }\end{array}\end{array}$ & $250-500 \mathrm{mg}$ BID & $10-14$ days \\
\hline
\end{tabular}

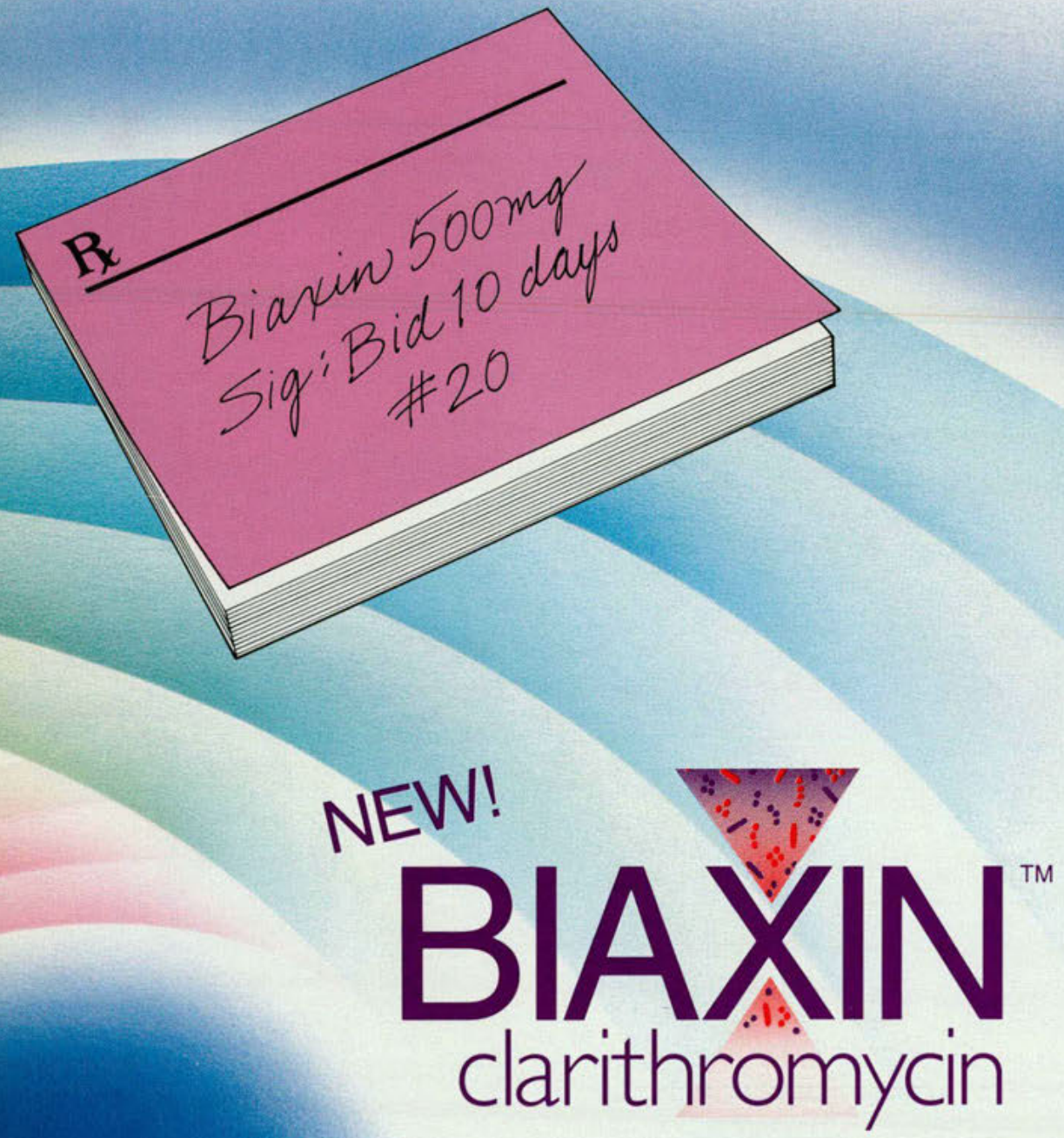

Spans the spectrum of erythromycin and the beta-lactams

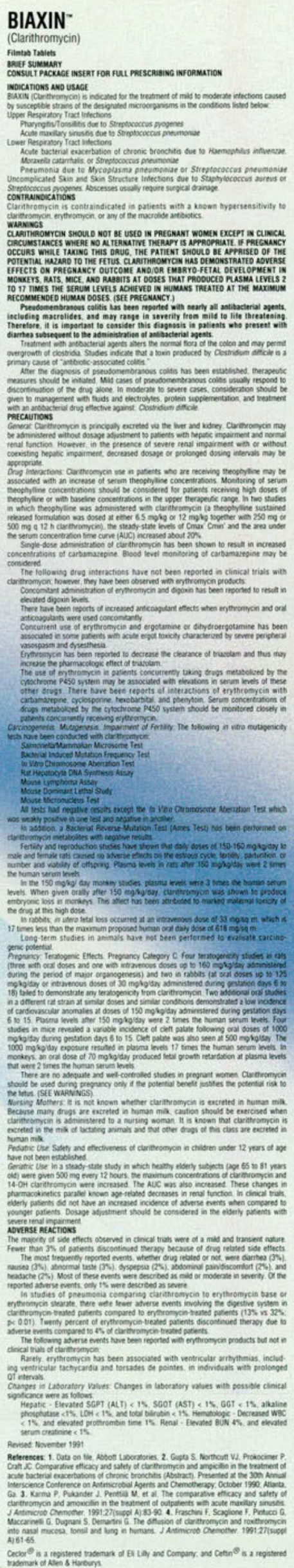




\section{AOA salutes Care-A-Van sponsors}

Two fully equipped mobile medical clinics are bringing free medical examinations and services to communities throughout the nation. Staffed by osteopathic physician volunteers and other trained technicians, the Care-AVans provide quality medical screening and consultation without charge.

The Care-A-Vans are funded by the American Osteopathic Association with contributions from its individual members. In addition, corporations and institutions have contributed to the Care-A-Van project, and the AOA gratefully acknowledges their commitment to better health for all Americans.

For more information on the Care-A-Vans contact:

John Perrin, Executive Director

\section{American Osteopathic Association}

142 E Ontario

Chicago, IL 60611-2864

(312) $280-5800$

\section{Sponsor-\$25,000}

Abbott Laboratories

American Osteopathic Board

of General Practice

Cellular One

Ford Trucks

Hoechst-Roussel Pharmaceuticals

Holiday Inns

ICI Pharmaceuticals Group

Lufkin Industries

College of Osteopathic Medicine of Oklahoma State University

SmithKline Beecham

Wyeth-Ayerst Laboratories

\section{Friend- $\$ 10,000$}

Pfizer, Inc.

\section{Contributor- $\$ 5,000$}

Norwich Eaton Pharmaceuticals, Inc.

Zimmer, Inc.

Parke-Davis

American College of General

Practitioners in Osteopathic

Medicine and Surgery

Kentucky Osteopathic Medical

Association

DuPont Pharmaceuticals

Hoffmann-La Roche, Inc.

Ortho Pharmaceutical Corporation

Adria Laboratories

Miles Inc.

Schering-Plough Corporation

Syntex Laboratories, Inc.

Johnson \& Johnson Orthopedic

The Purdue Frederick Company

MBNA-America

American Osteopathic College of

Radiology

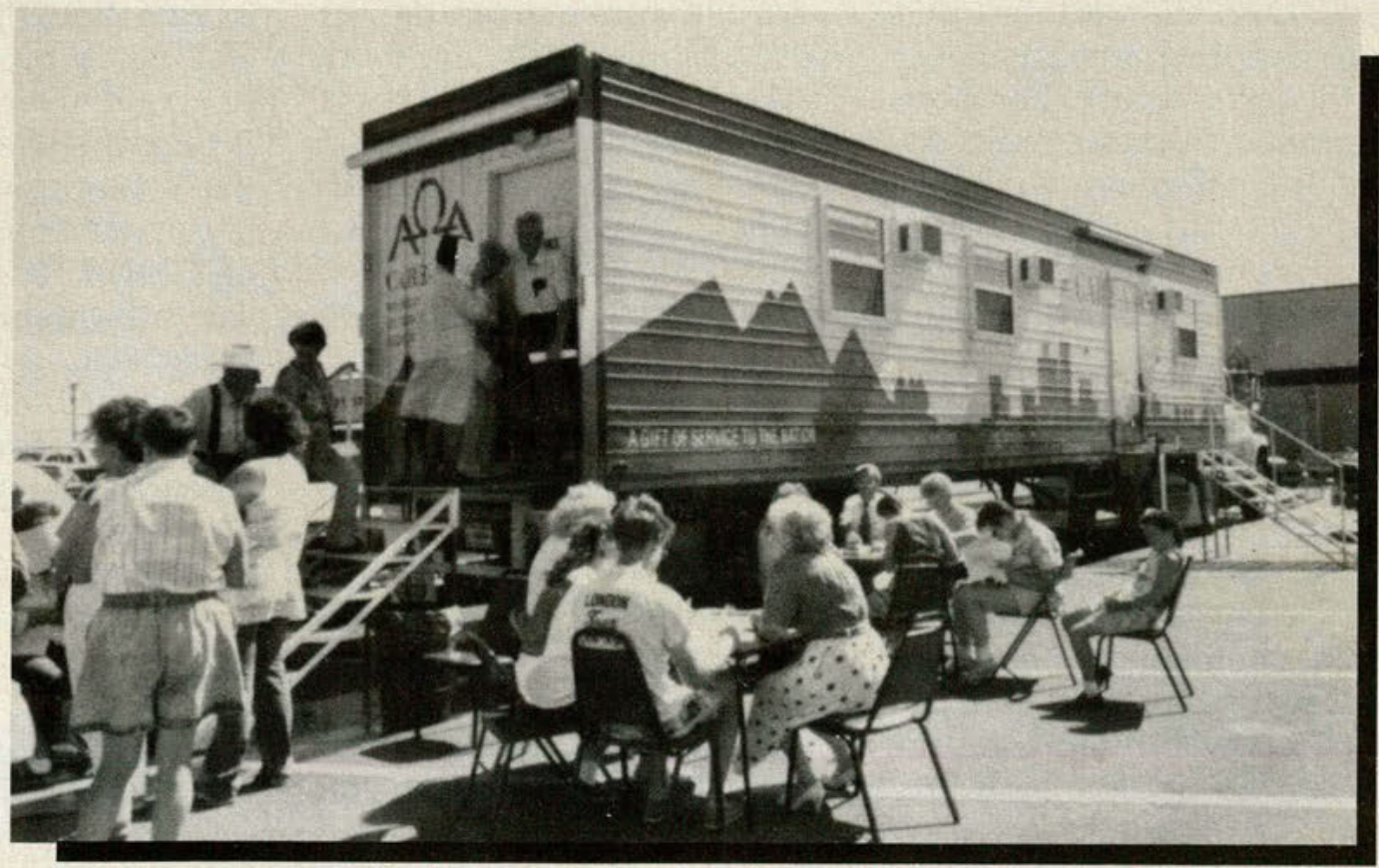

